\title{
A biophotonics course for freshman honors students
}

\section{Marco Molinaro, James Shackelford}

Marco Molinaro, James F. Shackelford, "A biophotonics course for freshman honors students," Proc. SPIE 9664, Ninth International Topical Meeting on Education and Training in Optics and Photonics, 96640N (24 October 2005); doi: $10.1117 / 12.2207723$

SPIE Event: Ninth International Topical Meeting on Education and Training in Optics and Photonics, 2005, Marseille, France 


\title{
Ref ETOP061
}

\section{A Biophotonics Course for Freshman Honors Students}

Marco Molinaro and James F. Shackelford,

Center for Biophotonics Science and Technology (CBST), One Shields Avenue, University of California, Davis, CA 95616 USA

\begin{abstract}
The National Science Foundation (NSF) funded Center for Biophotonics Science and Technology CBST) is collaborating with the Integrated Studies Honors Program (ISHP) at UC Davis to provide an introductory course to some of the top students in the freshman class. The course, IST 8A (Shedding Light on Life), was offered for the first time in Spring 2004 for the 2003-2004 ISHP class. A second offering was provided in Winter 2005 for the 2004-2005 ISHP class. This course is successfully increasing the educational, research, and training opportunities in the emerging field of biophotonics for high-achieving undergraduates at UC Davis.
\end{abstract}

biophotonics, photonics, education

\section{Keywords}

\section{Summary}

The Integrated Studies Honors Program (ISHP) at UC Davis is the oldest residential living/learning program in the University of California system, having been started in 1969. A steady increase in selectivity has led to the program being a cornerstone of campus efforts to recruit freshmen of exceptional talent. The traditional program goals are to provide excellent, personalized teaching; to integrate course offerings in the humanities, social sciences, and natural sciences; and to create a small residential community. These high achieving freshmen generally continue to be high achievers throughout their career at UCD. They graduate at a much faster pace than the general population. Also, one should note that the gpa at graduation for UCD students averages near 3.10. For the ISHP students, the average gpa at graduation is typically between 3.5 and 3.7. A significant fraction of each class (typically about $25 \%$ ) graduates with a gpa above 3.90 . The ISHP provides a close-knit community to a total of 114 students, the number available in the relatively new Bryan Miller Hall in the Segundo dormitory complex. Typically, a majority of the ISHP students receive Regents Scholarships, the most prestigious scholarships provided by the campus.

Each quarter, each ISHP freshman selects one of five different 4-unit courses under the general label of IST 8. Each IST 8 class has been pre-approved for General Education credit and is in the area of science/engineering (IST 8A), humanities (IST 8B), or social sciences (IST 8C). Each IST 8 class is capped at 25 students.

In addition, all 114 students take an introductory seminar (IST 9) focusing on a specific theme associated with assigned summer reading in the Fall Quarter. For example, the theme for IST 9 in Fall Quarter 2004 was "Campaign 2004 and All the President's Men" in which guest speakers covered the presidential campaign of 2004 and the students read Woodward and Bernstein's All the President's Men. The students also take one additional small (maximum enrollment of 15) seminar (also designated IST 9) during Winter or Spring Quarters. These various, small seminars are on topics defined by the faculty members in charge. The total of 14 units of IST coursework during the freshmen year represent nearly a third of the total workload for the typical freshman. 
The ISHP also provides upper division coursework on an elective basis for those students who went through the ISHP as freshmen. IST 190 is a seminar patterned after the Fall Quarter offering of IST 9 and is available to any ISHP student in his or her sophomore through senior years. IST $194 \mathrm{AH}, \mathrm{BH}$ are honors thesis courses available to ISHP students in both their junior and senior years. An ISHP instructor oversees the student's thesis along with a mentor from the student's home department.

The course, IST 8A (Shedding Light on Life), was patterned after the research themes of the National Science Foundation (NSF) funded Center for Biophotonics Science and Technology (CBST) along with the background needed to comprehend a broad definition of biophotonics.1 The course represents a general introduction to light, lasers, biology basics, and light/tissue interactions. Applications to diagnostics (tags), bioimaging, and therapies are illustrated, along with discussions of genes, cancer, and bionanophotonics. To engage the students, several experiential hands-on sessions are included with plans to expand such offerings in the future. This expansion will include original student group research projects involving spectroscopy of living matter and light/tissue interactions.

The introduction to the course includes an overview of the CBST and the overall Science and Technology Center (STC) program at the National Science Foundation. The STC program was instituted in 1987 and represented a fundamental shift in scientific funding policy in the United States,2 viz., a move from individual principal investigators to large, multi-investigator, multi-institutional centers. The relationship between the Center for Biophotonics Science and Technology (CBST) for which the University of California, Davis was the lead campus and the other STC's is discussed by Gellman, et al.3

The individual topics within the course are referenced to the introductory textbook on biophotonics by Paras Prasad.1 As the Prasad text is targeted to a more advanced audience, the lectures are intended to be self contained, with the outside reading in Prasad most beneficial for biological science and other science/engineering majors. All lectures are prepared as PowerPoint presentations and archived for convenient access by the students. Guest speakers from within the CBST community of scientific researchers are carefully selected as those who give effective introductory lectures. The IST 8A instructors work with the guest speakers to ensure that PowerPoint presentations for their talks are also archived.

The students in the class have access to a large body of archived material from the Education Program of CBST, as well as the PowerPoint lectures from their instructors and guest speakers. The archived material is especially useful to the students as they prepare a required term paper worth $25 \%$ of their course grade. All of the archived material on the Education site of the CBST web site is available to other interested educators.4 Access can be obtained by contacting Dr. Marco Molinaro, Chief Education Officer, CBST (mmolinaro@ucdavis.edu).

As noted by Gellman, et al. ${ }^{3}$, the annual meeting of the NSF Research Center Educators Network (NRCEN), a gathering of educational specialists from the various STC's and similar NSF-funded centers is a highly effective forum for sharing best practices for educational programs. In that forum, we became aware that an Engineering Research Center at the University of Illinois has a similar course to IST 8A for honors students interested in the theme of their center (earthquakes).

Of special note about IST $8 \mathrm{~A}$ is the fact that about half of the students are non-science majors taking the course as a General Education elective, while the other half are science 
and engineering majors taking the course because of their specific interest in the topic of biophotonics.

The ISHP students are selected on purely academic standards and are not a particularly diverse group. Nonetheless, the IST 8A class has attracted a large number of female students (67\% in the most recent class). Furthermore, the students have been active ambassadors for CBST, with several groups going out to the predominantly Hispanic Douglass Middle School in Woodland, California (ten miles north of Davis) and presenting introductory biophotonics concepts to seventh and eighth grade science students. CBST educators provide the IST 8A students with an introduction to learning theories and teaching techniques prior to the classroom visits. Groups of students have also presented to the general UC Davis student body and at community colleges with highly diverse student bodies in the Sacramento area.

Each class is evaluated by a standard student survey, and we provide additional assessment questions and surveys to the students during the quarter. Student satisfaction was high in the first offering, and several refinements were made based on their suggestions. The assessment of the second offering indicates that the course was even more effective in its second year.

There are also some very positive anecdotal data from the class. For example, one female student from the first year's class changed her major to the biological sciences as a result of Dr. Edie Zusman's lecture and this past summer had an internship in Zusman's laboratory. Also, the first ISHP student to be involved in CBST (and a tutor [undergraduate teaching assistant] to the current ISHP students) has just graduated in Optical Science and Engineering and began graduate study at Harvard in the optics field in Fall 2005.

Another student from the first year's class is beginning the upper division honors thesis courses (IST $194 \mathrm{AH}, \mathrm{BH}$ ) in the 2005-2006 academic year. In conclusion, we are quite optimistic that exposing the very best undergraduates at UC Davis to CBST will provide a number of other excellent undergraduate researchers and future biophotonics professionals.

The Center for Biophotonics Science and Technology (CBST) is funded by the National Science Foundation and is managed by the University of California, Davis under Cooperative Agreement No. PHY 0120999.

\section{References}

1. Paras N. Prasad, Introduction to Biophotonics, Wiley-Interscience, Hoboken, NJ, 2003.

2. Science and Technology Centers: Integrative Partnerships, NSF Document 03-550, National Science Foundation, Arlington, VA, 2003.

3. Joel Gellman, Srini Vasan, Robert Hall, Don Goodwin, Dennis Matthews, Marco Molinaro, and James F. Shackelford, "Development of a Biophotonics Option within a Photonics Technology Degree Program," in this proceedings.

4. http://biophotonics.ucdavis.edu

Contact: jfshackelford@ucdavis.edu; phone 1530 752-4030; fax 1530 752-9554; http://cbst.ucdavis.edu 